\title{
In situ quantification of supraglacial cryoconite morphodynamics using time-lapse imaging: an example from Svalbard
}

\author{
Tristram D.L. IRVINE-FYNN, ${ }^{1,2}$ Jonathan W. BRIDGE, ${ }^{3}$ Andrew J. HODSON ${ }^{1}$ \\ ${ }^{1}$ Department of Geography, University of Sheffield, Winter Street, Sheffield S10 2TN, UK \\ ${ }^{2}$ Institute of Geography and Earth Sciences, Aberystwyth University, Penglais Campus, Aberystwyth SY23 3DB, UK \\ E-mail: tdi@aber.ac.uk \\ ${ }^{3}$ Cell-Mineral Research Centre, Kroto Research Institute, University of Sheffield, Broad Lane, Sheffield S3 7HQ, UK
}

\begin{abstract}
There is growing recognition of the significance of biologically active supraglacial dust (cryoconite) for glacial mass balance and ecology. Nonetheless, the processes controlling the distribution, transport and fate of cryoconite particles in the glacial system remain somewhat poorly understood. Here, using a 216 hour time series of plot-scale $\left(0.04 \mathrm{~m}^{2}\right)$ images, we quantify the small-scale dynamics of cryoconite on Longyearbreen, Svalbard. We show significant fluctuations in the apparent cryoconite area and dispersion of cryoconite over the plot, within the 9 day period of observations. However, the net movement of cryoconite across the ice surface averaged only $5.3 \mathrm{~mm} \mathrm{~d}^{-1}$. Highresolution measurements of cryoconite granule motion showed constant, random motion but weak correlation with meteorological forcing factors and no directional trends for individual particle movement. The high-resolution time-series data suggest that there is no significant net transport of dispersed cryoconite material across glacier surfaces. The areal coverage and motion of particles within and between cryoconite holes appears to be a product of differential melting leading to changes in plotscale microtopography, local meltwater flow dynamics and weather-dependent events. These subtle processes of cryoconite redistribution may be significant for supraglacial albedo and have bearing on the surface energy balance at the glacier scale.
\end{abstract}

\section{INTRODUCTION}

The surface of Arctic glaciers typically exhibits a widespread yet spatially variable coverage of granular biologically active dust termed cryoconite. Cryoconite consists of significant quantities of organic material, algae and bacteria bound together in and around inorganic, mineral particles (Takeuchi and others, 2001a, 2010; Hodson and others, 2008; Langford and others, 2010). The presence of such material in the supraglacial landscape has a profound effect upon ice melt through its influence on surface albedo (e.g. Bøggild, 1997; Takeuchi and others, 2001b; Takeuchi, 2009; Bøggild and others, 2010) and on nutrient cycling, particularly nitrogen and carbon (Hodson and others, 2005a, 2007, 2010; Stibal and others, 2008; Anesio and others, 2009, 2010). There is a growing literature examining cryoconite microbial ecology and its spatial variability (e.g. De Smet and Van Rompu, 1994; Säwström and others, 2002; Christner and others, 2003; Mueller and Pollard, 2004; Porazinska and others, 2004; Stibal and others, 2006; Anesio and others, 2007; Foreman and others, 2007; Langford and others, 2010; Segawa and others, 2010; Edwards and others, 2011). Recent work has highlighted the intimate coupling between cryoconite and supraglacial hydrology both in Arctic and Antarctic settings (Fountain and others, 2004; Hodson and others, 2007; Irvine-Fynn, 2008; MacDonell and Fitzsimons, 2008; Edwards and others, 2011). Glaciers are increasingly understood to represent an important source of labile carbon to connected hydrological and ecological systems (Hood and others, 2009). Yet, despite this growing perception, the processes and conditions controlling cryoconite distribution, transport and fate in the supraglacial environment remain relatively poorly understood. The residence time of cryoconite on ice surfaces, lateral rates of movement of cryoconite towards ice margins or supraglacial streams, and the interactions of particles with each other and with ice surface microtopography are all, to date, unquantified.

Using imagery acquired from a camera mounted on an unmanned aerial vehicle (UAV), Hodson and others (2007) demonstrated a spatial gradient in the ratio of cryoconite form over Midtre Lovénbreen, a small valley glacier in Svalbard: distributed cryoconite forms were prevalent at lower elevations while isolated cryoconite holes dominated up-glacier areas. This contrast was inferred to be the result of hydrological mobilization: at lower elevations, greater melt rates and marginally steeper surface slopes result in frequent or periodic disruption and redistribution of cryoconite holes and their contents (Hodson and others, 2007, 2008). Exploring this in greater detail, Hodson and others (2010) and Irvine-Fynn and others (2010) used plot-scale image data collected from Longyearbreen, another valley glacier in Svalbard. They conjectured a net downslope movement of cryoconite interspersed with 'relief inversions'; during sunny periods cryoconite melts into the ice due to preferential radiation absorption, creating depressions (Mclntyre, 1984; Podgorny and Grenfell, 1996; Bøggild and others, 2010) and lessening the apparent cryoconite area relative to the ice surface plane. Conversely, ice melt through localized water flow, and during cloudy periods when dominated by turbulent energy fluxes, results in the melt-out of cryoconite (Mclntyre, 1984; Hodson and others, 2008), thereby reducing the contrasts in microtopography and increasing its apparent area.

Here, building upon the earlier work of Irvine-Fynn and others (2010) and Hodson and others (2010), we present a full exploration of a 9 day hourly time-series image set for a typical supraglacial plot. The datasets were acquired with commercially available digital cameras in an Arctic setting, 
where during summer months cryoconite holes tend not to display ice lids. The aim of this work is to quantify the nature of cryoconite mobility within the supraglacial environment, by conducting the first detailed plot-scale analysis of cryoconite granule distribution and mobility under multiple diurnal cycles.

\section{MATERIALS AND METHODS}

\section{Field site and cryoconite imaging}

Over a 9 day period (21-29 July 2008; day of year (DOY) 203-211) a time-lapse sequence of 216 images was collected at a plot on Longyearbreen $\left(78^{\circ} 10^{\prime} 49^{\prime \prime} \mathrm{N}\right.$, $\left.15^{\circ} 30^{\prime} 21^{\prime \prime} \mathrm{E}\right)$. The image datasets were captured as uncompressed 7.08 Mpix $(3072 \times 2304)$ digital colour $(R G B)$ JPEG files, using a Pentax Optio WP30 digital camera triggered at hourly intervals. The camera installation comprised a vertical aluminium pole drilled and frozen into the glacier ice with the camera attached to a crossbar; the arrangement was immobile although the ice surface ablation resulted in a change in the camera-to-ice distance of $\sim 0.4 \mathrm{~m}$ over the imaging period. The plot, averaging $\sim 0.12 \mathrm{~m}^{2}$, was considered to be representative of an ablating Arctic glacier surface, exhibiting an irregular, time-variable microtopography. The imaged plot sloped $2^{\circ}$ down-glacier to the northeast (52 ${ }^{\circ}$ from north). A $47 \mathrm{~mm}$ filter paper was placed on the ice surface to act as a control for image scale; the filter paper was present throughout the image sequence. The camera was oriented such that the local surface slope was parallel to the vertical $(\mathrm{Y})$ axis in images. The broader glaciological characteristics of the site are described by Etzelmüller and others (2000), while subsets of the data and further study-site details have been detailed previously (Hodson and others, 2010; Irvine-Fynn and others, 2010).

Concurrent meteorological data were collected at hourly intervals. At the camera location, time series of shortwave incident radiation, IR, and reflected radiation were recorded using horizontal, cross-calibrated up- and down-looking hemispheric pyranometers (Middleton and Skye Instruments, respectively). Supplementary meteorological data including air temperature, $T_{\mathrm{a}}$, were taken from the Gruvefjellet automatic weather station (AWS) located $\sim 4 \mathrm{~km}$ north of Longyearbreen but at an elevation similar to that of the imaging site.

\section{Digital image processing}

The purpose of image pre-processing was to provide a dataset normalized to a common spatial scale to account for changes in the position of the camera relative to the ablating ice surface. Analysis of this processed dataset was conducted with two objectives: (1) quantification of changes in the fractional areal coverage and distribution of cryoconite over the plot at hourly and diurnal timescales; and (2) quantification of individual particle motion vectors at hourly resolution over the course of each day. We used the public domain Java-based image processing software ImageJ (W.S. Rasband, http://imagej.nih.gov/ij/).

\section{Pre-processing}

Image pre-processing followed the method outlined by Irvine-Fynn and others (2010) for supraglacial cryoconite. Briefly, RGB colour images were split into red, green and blue colour channels, and blue channel data (as 8-bit, greyscale) retained for analysis since, in this colour space, red/brown cryoconite appears darker (lower pixel values) than surrounding blue, white and grey ice and shadows. The 216 images were grouped into 24-image 'stacks', each representing 1 day (midnight to midnight). Subsequent analyses were conducted on each 24-image stack separately.

\section{Rescaling to normalize spatial scale}

The spatial resolution of each image (pixels $\mathrm{mm}^{-1}$ ) was obtained by recording the apparent diameter (in pixels) of the $47 \mathrm{~mm}$ filter disc. The difference between this value and a target resolution of 10 pixels $\mathrm{mm}^{-1}$ was calculated and used as a scaling factor to normalize all images to the same size and spatial resolution. This step is essential for monitoring relative changes in position of cryoconite within the field-ofview over time. The final processed images showed a region of interest (ROI) centred on the centre of each original camera image, measuring $\sim 0.2 \mathrm{~m} \times 0.2 \mathrm{~m}$. This process does not account for changes in position of the field-of-view due to unconstrained camera 'wobble'. To characterize this, we tracked and triangulated the positions of the five least-mobile cryoconite granules (see 'Particle motion' below) through each 24-image stack to obtain the apparent motion of a 'virtual' fixed reference point. The mean displacement of this point during any 24 hour period was only $2.04 \pm 1.04 \mathrm{~mm}$, with the exception of DOY 208 when a manual adjustment in camera position resulted in $\sim 36 \mathrm{~mm}$ displacement of the field of view. In this instance, this latter displacement vector was subtracted from subsequent particle position data.

\section{Spatial moments}

Regions of cryoconite were classified using pixel thresholding as described by Irvine-Fynn and others (2010). The total apparent cryoconite area (ACA; $\mathrm{m}^{2}$ cryoconite $/ \mathrm{m}^{2}$ plot area) was evaluated as the fraction of pixels classified as cryoconite in each rescaled image. For each image, the centre of mass (COM) and $\mathrm{XY}$ covariance (a measure of dispersion of mass about the centroid) were calculated using built-in ImageJ functions: these two measures are the first and second spatial moments, respectively, and were used to quantify the net movement and distribution of cryoconite mass across the field of view.

\section{Image differencing}

To visualize changes in the spatial distribution of cryoconite across the plot over time, images obtained at $1200 \mathrm{~h}$ on DOY 203, 205, 207, 209 and 211 were processed to show areas of cryoconite loss and gain. Using the 'Image arithmetic' function in ImageJ, data for DOY 205 were subtracted, pixel-by-pixel, from data at DOY 203, resulting in an image in which negative pixel values indicated change from cryoconite (dark) to ice (bright), positive pixel values indicated change from ice to cryoconite, and zero values indicated regions of no substantial change. The procedure was repeated for successive image pairs at 48 hour intervals to DOY 211.

\section{Particle motion}

In each 24-image stack, the movement of a random selection of 50 individual cryoconite granules was tracked using the ImageJ plug-in MTrackJ (E. Meijering, http:// www.imagescience.org/meijering/software/mtrackj/). The origin, hourly displacement $(\mathrm{mm})$ and total displacement from the origin $(\mathrm{mm})$ of each granule were recorded and 


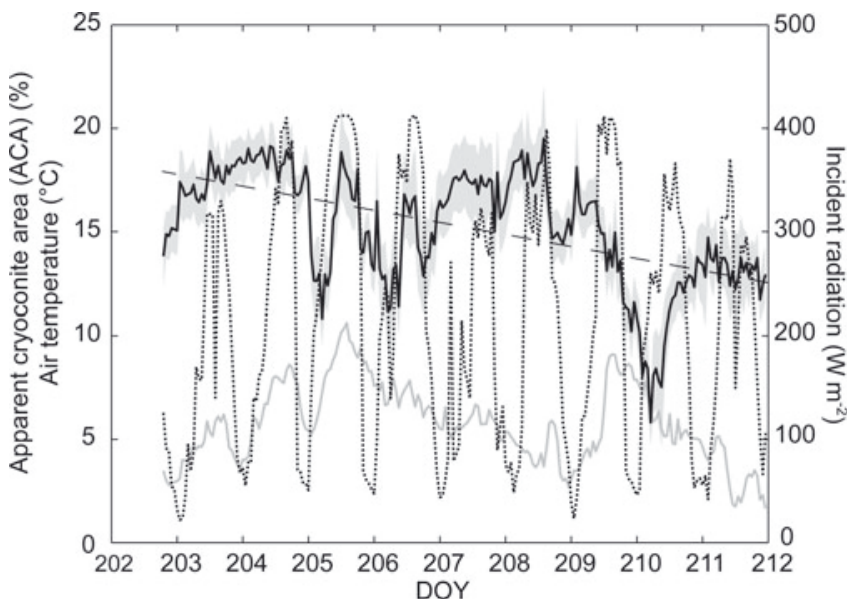

Fig. 1. Hourly time series of ACA (black curve) including uncertainty (greyed area), incident radiation at the site (dotted curve) and air temperature at similar elevation (data from Gruvefjellet AWS: grey curve).

averaged to obtain characteristic particle-motion data at hourly and diurnal timescales. From these data, motion path-length and -direction vectors could be derived.

\section{RESULTS AND ANALYSIS}

\section{Temporal variation in cryoconite areal coverage}

Figure 1 illustrates the temporal change in ACA compared with air temperature, $T_{a}$, and incident solar radiation, IR, the primary meteorological variables assumed to drive cryoconite mobility through ice melt. Note that ACA for a subset of these data was previously reported but used a subtly larger ROI within the measurement plot, so values of ACA in comparable images are slightly different (mean difference in ACA is $2.6 \pm 1.3 \mathrm{~m}^{2} \mathrm{~m}^{-2}$ (cf. Irvine-Fynn and others, 2010).

The ACA showed substantial fluctuations (maxima $\sim 0.195$ and minima 0.058) with $\sim 4$ day periodicity. Correlations between ACA and IR or $T_{\mathrm{a}}$ were weak $(r=-0.002$ and $r=-0.02$, respectively), and covariance between IR and $T_{\mathrm{a}}$ was only moderate $(r=0.4)$. Improvements in the correlation coefficients were found through cross-correlation: ACA lagged IR ( $r=0.27$, lag 14 hours) and $T_{\mathrm{a}} \quad(r=0.37$, lag 13 hours). Within the 9 day period of observations, ACA showed a statistically significant decrease $\left(r^{2}=0.31, p<0.01\right)$. However, given the relatively large fluctuation within this period, it is impossible to extrapolate a longer-term trend on this basis.

\section{Spatial variation in cryoconite areal coverage}

Figure 2 shows the change in the spatial distribution of cryoconite within the ROI for sequential 48 hour intervals processed using image differencing as described above. These data emphasize the substantial reworking of the cryoconite deposit within the plot, despite the fact that ACAs measured at the start and end of the observation period are only marginally different. Figure 3 a plots the COM position over time and clearly indicates a trend in cryoconite movement at $57.1^{\circ}$ from the downslope direction. Averaged over the observation period, the daily rate of COM motion is $5.3 \mathrm{~mm}$, of which $2.9 \mathrm{~mm}$ is downslope (Y-direction) and $4.4 \mathrm{~mm}$ cross-slope (X-direction). The concurrent trend in the second spatial moment away from zero (Fig. 3b) indicates that cryoconite became more distributed or dispersed across the ROI, although like ACA this dataset showed strong fluctuations on hourly and diurnal timescales and the trend within the observation period cannot be extrapolated to longer timescales.

\section{Motion of individual cryoconite granules}

The motion tracks recorded for individual cryoconite granules were used to generate an hourly time series of mean particle motion rate $\left(\mathrm{mm} \mathrm{h}^{-1}\right)$. Plotted alongside the IR time series (Fig. 4), these data show an apparently diurnal signal. However, the correlation between the datasets, although significant, was weak $(r=0.25)$, as was the correlation with $T_{\mathrm{a}}(r=0.27$; data not shown). Cross-correlation analysis suggested a lag time of 1 hour for mean granule movement against both IR and $T_{\mathrm{a}}$ ( $r$ increased by 0.02 for both variables). Accumulated over each day, the net particle displacement of the 50 measured granules is shown in Figure 5a. Over the period of observations, this mean daily particle displacement was $8.6 \mathrm{~mm}$, but the orientation of granule movement vectors showed no preferential direction, either downslope $\left(180^{\circ}\right)$ or in the direction of net cryoconite COM movement shown in Figure $3 a\left(123^{\circ}\right)$. However, the magnitude of mean daily particle displacement did, broadly, appear to correspond to the presumed driving variable, IR (Fig. 5b).
203-205

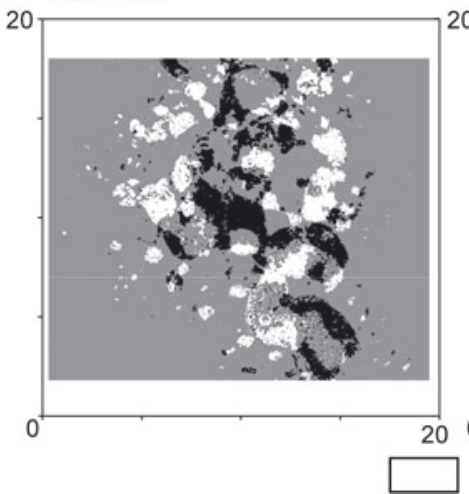

205-207

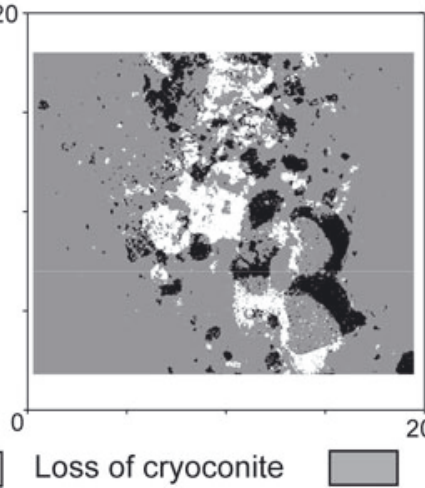

207-209

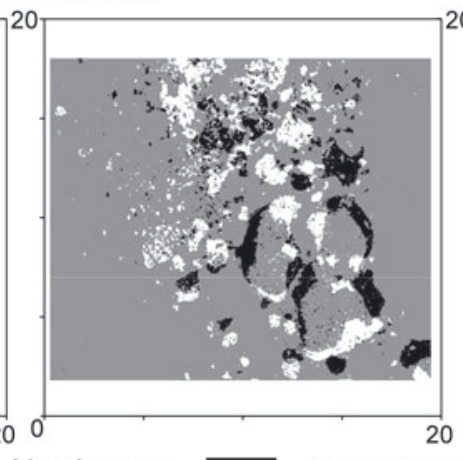

209-211

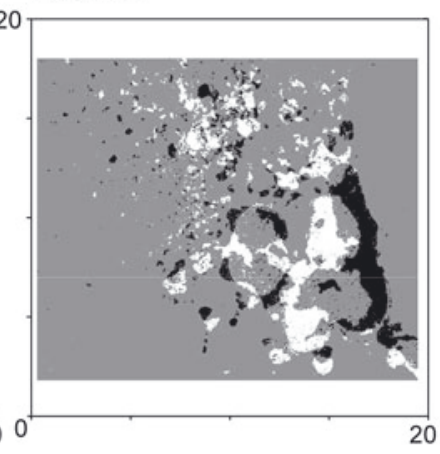

No change

Fig. 2. Difference images highlighting spatial changes in cryoconite distribution at 48 hour intervals showing substantial reworking of the deposits. Note that downslope is parallel to the Y-axis, top to bottom. 

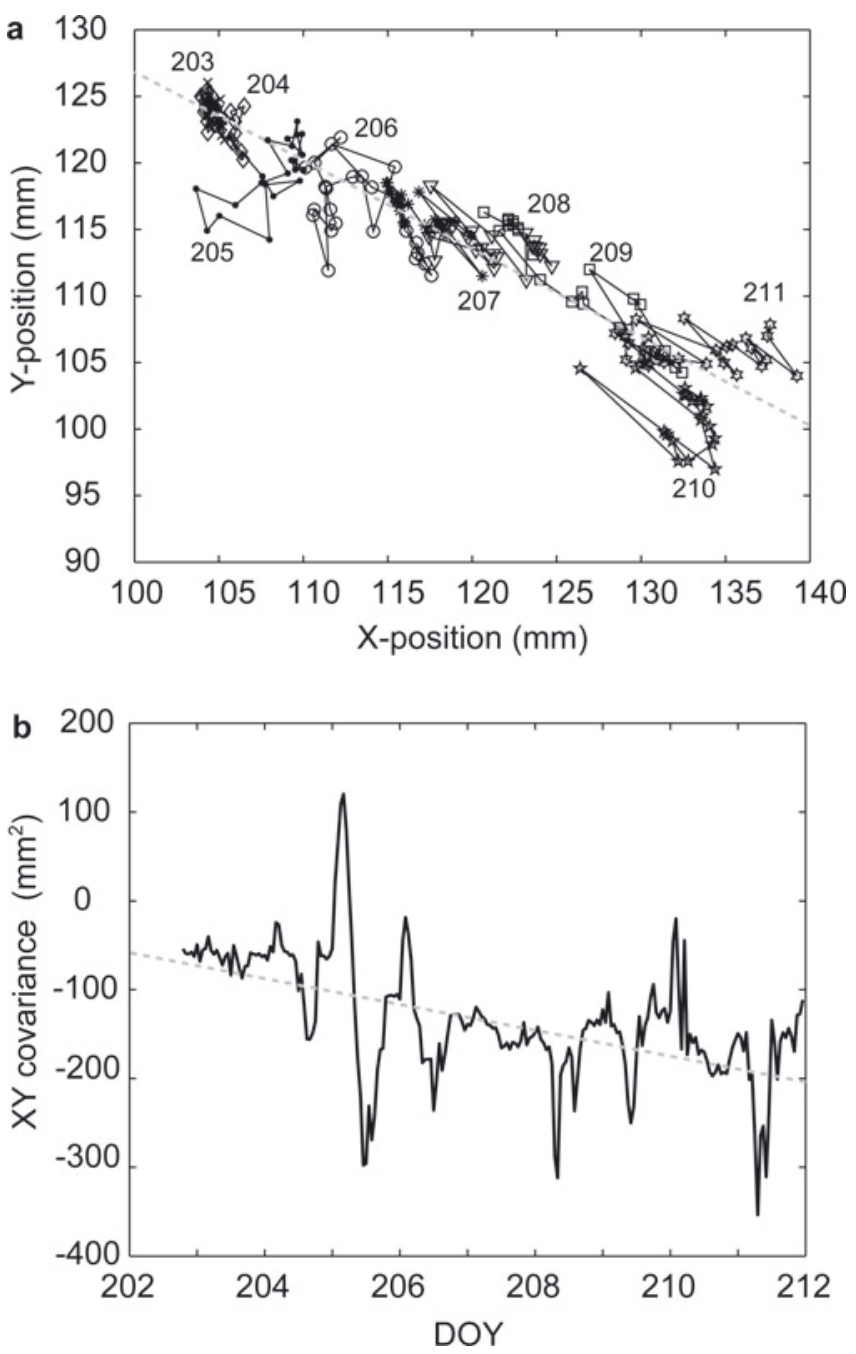

Fig. 3. Plots of the change in (a) COM for cryoconite within the $\sim 0.04 \mathrm{~m}^{2} \mathrm{ROI}$, with each day highlighted with differing marker styles, and (b) the XY covariance indicating the degree of cryoconite dispersion over the ROI.

\section{Cryoconite mobility and supraglacial energy balance}

A full energy-balance model (EBM) estimating hourly energy fluxes to the ice surface was run following Brock and Arnold (2000). Site-specific details were used and adjustments made to the incident solar radiation algorithm to account for high-latitude solar geometry (after Kreith and Kreider, 1978). The time series of albedo (derived from the two pyrometer records) was corrected for surface slope effects following Arendt (1999) and included within the model; a static value of $0.0253 \mathrm{~mm}$ was employed as a representative ice roughness (Hodson and others, 2005b). Particle motion compared with energy-balance components at hourly timescales revealed correlations $|r|<0.02$ for sensible and latent heat fluxes, and an inverse relationship with longwave radiative flux $(r=-0.14)$; a stronger positive correlation between motion and shortwave radiation is apparent $(r=0.25$; no lag was found with cross-correlation analysis), and regression analysis showed the slope of the relationship was significantly different from zero $(p=0.05)$. Figure 6 suggests that a number of outlying data points may conceal a more robust trend. These analyses, albeit with weak associations, support the assertion that, at the hourly timescale, shortwave radiation may provide a driving force for cryoconite granule redistribution.

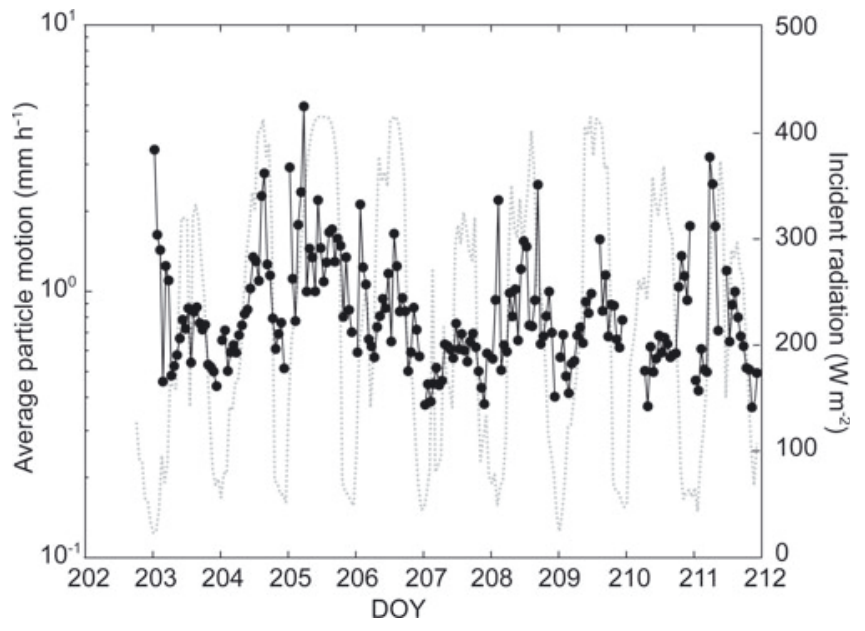

Fig. 4. Mean particle displacement as a function of time for sample of 50 random cryoconite granules; the coincident series of IR at the site is shown for comparison (grey dotted curve). Note that the velocity series is not continuous: data were examined at 24 hour intervals ( $n=23$ for 1 day), and images for which rescaling uncertainty occurred were omitted to avoid introduction of bias.

Crucially, comparison between the ACA time series and the plot-scale albedo measurements (Fig. 7) shows a significant relationship between the two variables over the 9 day period of observation $\left(r^{2}=0.243, p<0.05\right)$. This finding associates the process of relief inversions (the apparent melting in and out) and the fluctuations in cryoconite coverage and dispersion with ice surface albedo. The wider implication of this association is that the shortterm variability in ACA may be a significant contributing factor in defining short-term variability in the energy balance over the snow-free glacier ice and thus provide some control on the variability in melt rates.

\section{DISCUSSION AND CONCLUSIONS}

We have used quantitative analysis of time-lapse digital image data to examine, in detail, a small (sub-metre) patch of dispersed cryoconite at unprecedented spatial and temporal resolution over a 9 day period. Cryoconite coverage varied substantially at frequencies of several days, which corresponds to typical synoptic weather pattern periodicity in western Svalbard (e.g. Hanssen-Bauer and others, 1990; Hodson and others, 1998). Although, statistically, relationships were weak, the analyses suggest some degree of meteorological forcing of the ACA, with an inverse and 1 hour lagged relationship between energy receipt and ACA, suggestive of relief inversion processes at the diurnal scale. The fluctuation in ACA is coupled with a progressive but rather small lateral movement in the centre of mass for the cryoconite across the plot. Assuming a typical 70 day High Arctic melt season (Hodson and others, 2000), this movement is insignificant at the scale of the glacier, being equivalent to $0.37 \mathrm{~m} \mathrm{a}^{-1}$. Therefore, based on these preliminary data from a typical patch of dispersed cryoconite, and knowledge of distinctly linear relationships between cryoconite area and mass (Cook and others, 2010), we find little evidence for mass transfer of significant quantities of cryoconite across the ice surface by 'washing' by meltwater flow over (or through) the so-called 'weathering crust' (Müller and Keeler, 1969). This stability has significant 
a 203

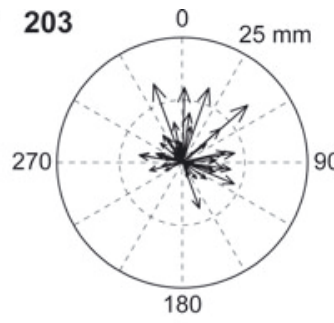

206

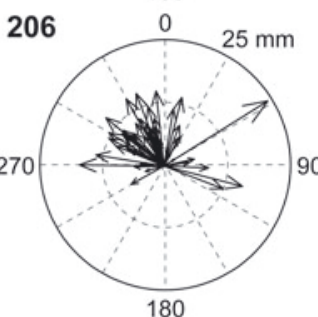

209

$0 \quad 25 \mathrm{~mm}$

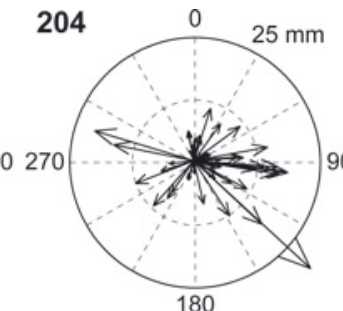

207

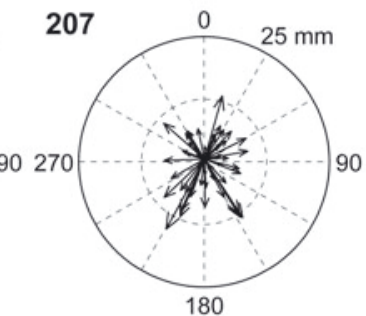

208

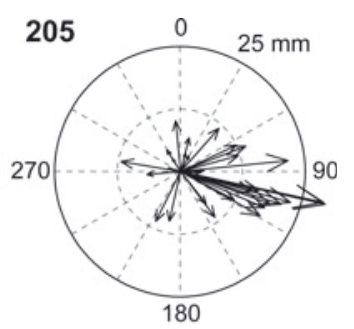

208
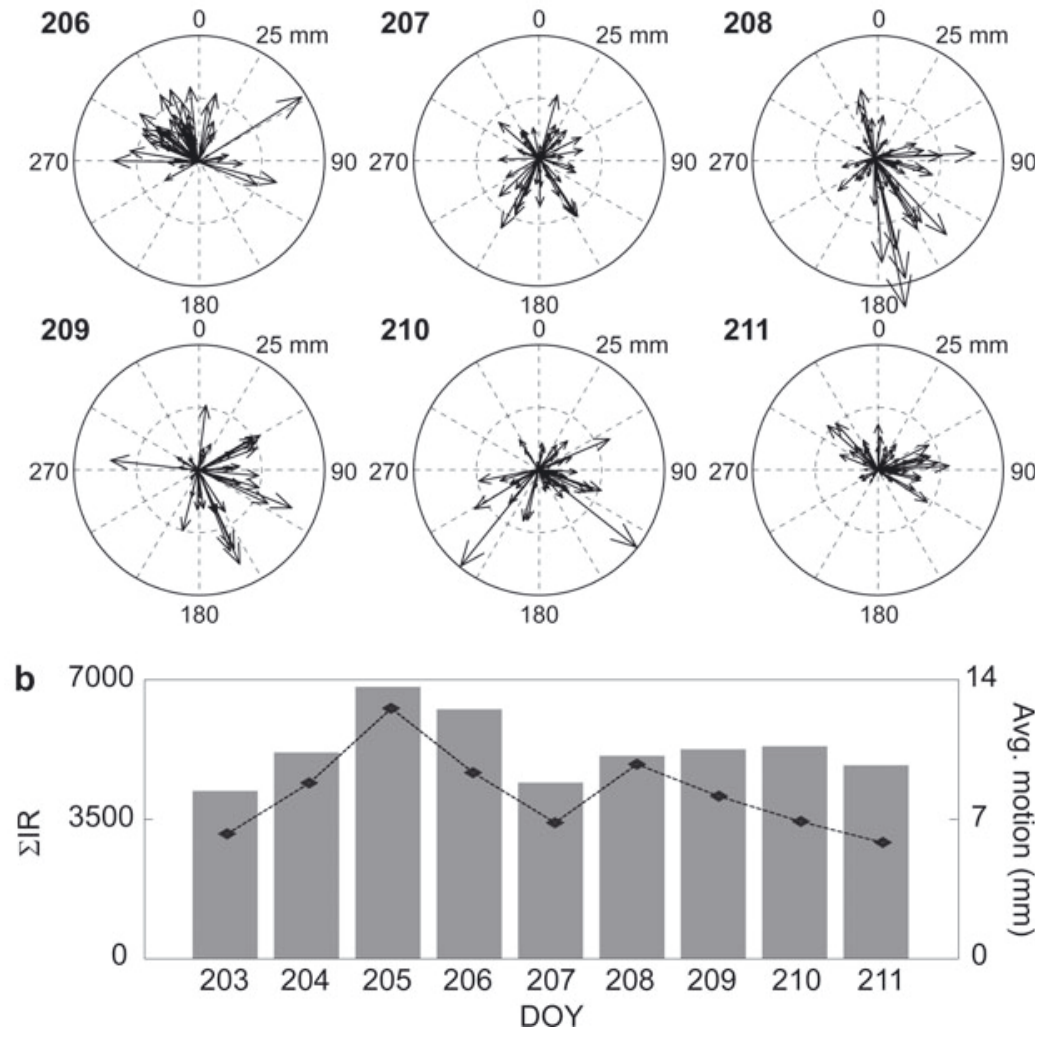

Fig. 5. (a) Compass plots illustrating net daily motion (magnitude and direction) for 50 cryoconite granules for DOY 203-211. Outer plot limits are $25 \mathrm{~mm}$, with a $12.5 \mathrm{~mm}$ axis marked; downslope is oriented at $180^{\circ}$. (b) Daily sum of hourly-averaged IR data (bars) plotted alongside daily mean particle displacement (curve).

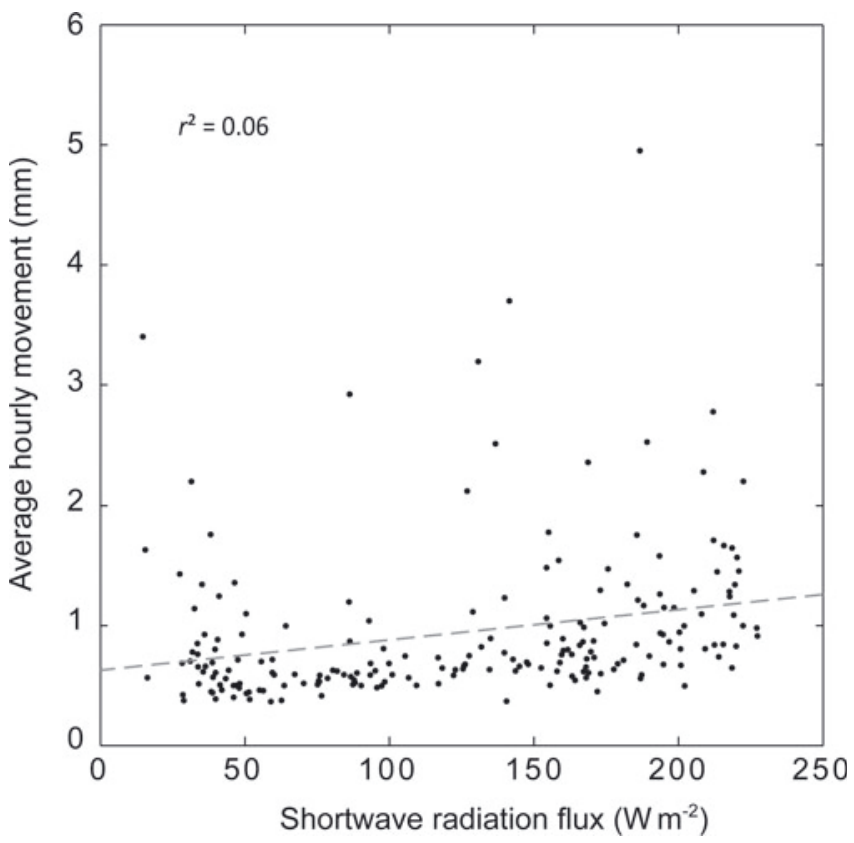

Fig. 6. Scatter plot of hourly particle motion (from a sample of 50 granules) vs shortwave radiation flux predicted using an adjusted Brock and Arnold (2000) energy-balance model.

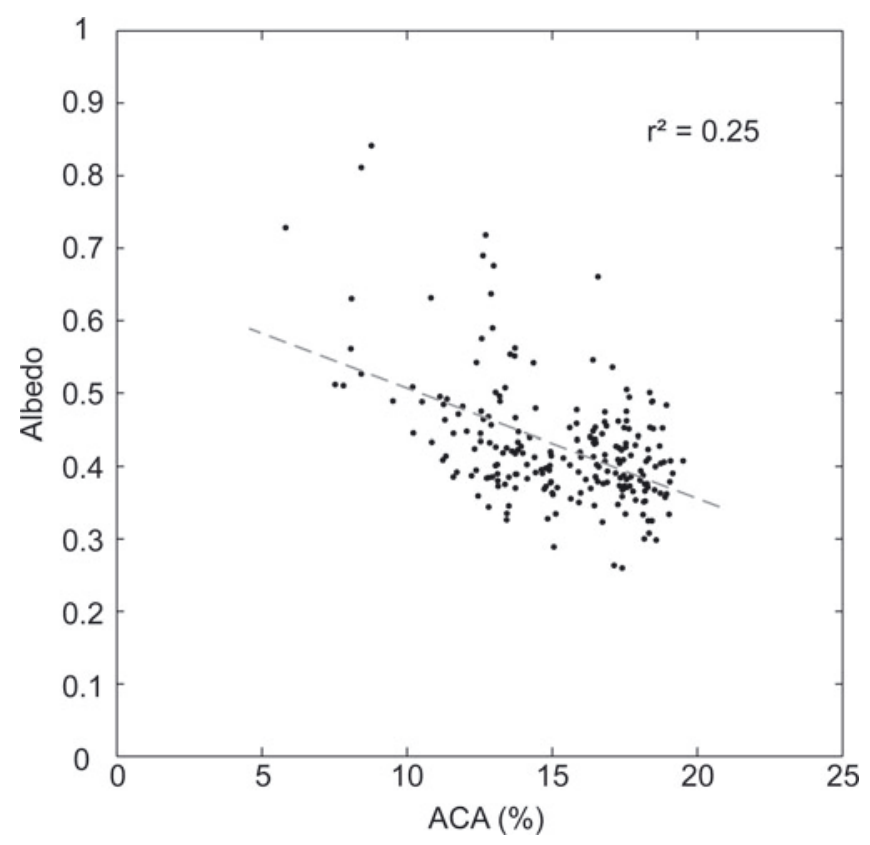

Fig. 7. Scatter plot of ACA vs albedo (the ratio of reflected/incident radiation) corrected for the effect of surface slope. 


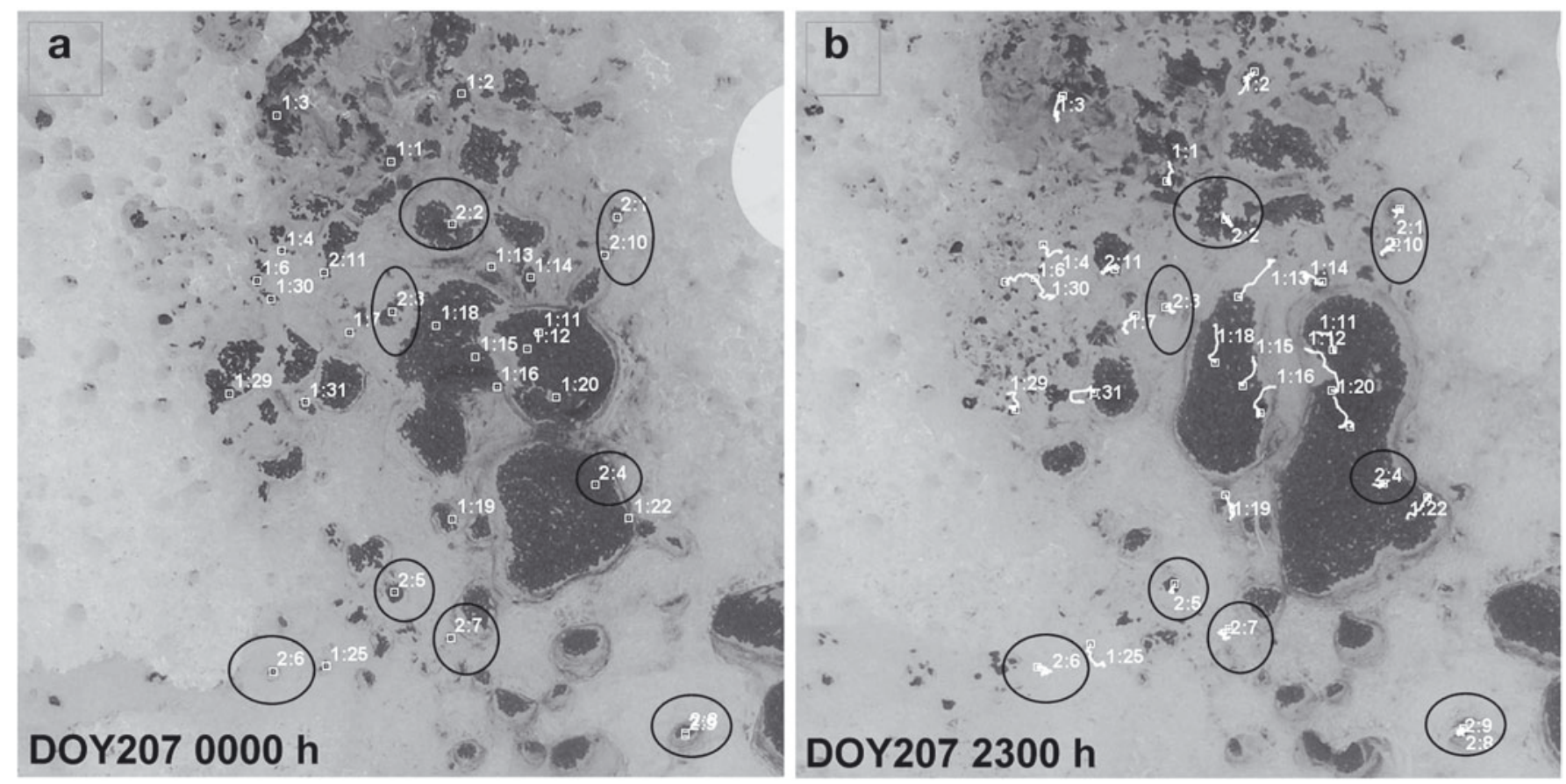

Fig. 8. Cryoconite distribution at 0000 and $2300 \mathrm{~h}$ on DOY 207, showing initial positions (a) and motion tracks (b) of selected cryoconite granules. Of these, a subset (labelled 2: $n$ and circled in black) show small, random 'shuffling' over the 23 hour period. Others (labelled 1:n) are associated with significant reworking of cryoconite hole morphology.

implications for the cryoconite ecosystem, in that it increases the effective residence time of cryoconite on the glacier surface, particularly compared with meltwater fluxes, thereby enabling the formation of complex microbial communities, which are tolerant of the prevailing conditions (Edwards and others, 2011).

Conversely, the motion of individual cryoconite particles within the patch was pervasive, persistent and apparently random. Although the daily mean particle displacement was of the same order as the net cryoconite movement (8.6 and $5.3 \mathrm{~mm} \mathrm{~d}^{-1}$, respectively), the mean distance travelled by granules was significantly larger, at $18.3 \mathrm{~mm} \mathrm{~d}^{-1}$, emphasizing the tortuosity of granule motion. Inspection of individual motion tracks (Fig. 8) indicates that motion was dominated by two processes: random 'shuffling' of particles (leading to very small net displacement) and larger, rapid, directed displacements of particles associated with melting-induced flows, often between neighbouring holes. Critically, then, the major control on granule motion appears to be the microtopography of the weathering crust and the relative elevations of perched water levels generated and then released by progressive (or fluctuating) processes of relief inversion and local hydraulics.

Importantly, the observations presented here relate to a patch of associated but distributed cryoconite holes, which contrasts in form with other distributions of cryoconite, such as in-stream and fully dispersed cryoconite (Hodson and others, 2007), deep, isolated holes, or the larger cryoconite deposits observed in the field as 'cryoconite mantles' (Hodson and others, 2008) or lobate forms. Additional data are required to characterize the morphodynamics of cryoconite in these forms, and over longer timescales, before more general estimates of cryoconite redistribution and transport phenomena at the glacier scale can be drawn. However, the methods we present here provide a rapid, reproducible protocol for collecting and analysing such datasets.

A key disadvantage of the current imaging method is the lack of quantitative depth perception from a single camera. Small-scale photogrammetry is under development to address this issue and enable more detailed quantitative investigation of the development of ice surface microtopography and cryoconite coverage over the course of the melt season. Our preliminary analyses here indicate that this is a significant driver of cryoconite granule redistribution and hence of patch-scale ACA and, more significantly, glacier surface albedo fluctuations. Quantifying and understanding the small-scale, diurnal interactions between cryoconite granules and microtopography, using time-lapse image sequences, may thus critically enhance our ability to model the dynamic coupling between cryoconite, surface roughness, albedo and melt generation over larger areas, at seasonal timescales.

\section{ACKNOWLEDGEMENTS}

Fieldwork was funded by the Leverhulme Trust Research Fellowship RF/4/RFG/2007/0398 awarded to A.J.H. T.I.-F. and A.J.H. acknowledge UK Natural Environment Research Council (NERC) Standard Grant NE/G006253/1, and the RGS Peter Fleming Award (2009) enabled thoughtful discussions in the field. T.I.-F. also recognizes backing from the Climate Change Consortium of Wales (C3W) initiative, enabling completion of the manuscript. J.W.B. was supported in this work by S. Banwart and NERC grant NE/ C521001/1. The Gruvefjellet meteorological data were made available by researchers based at The University Centre in Svalbard (UNIS). A. Edwards is thanked for useful comments on the manuscript. Comments from two anonymous reviewers are appreciated. 


\section{REFERENCES}

Anesio, A.M., B. Mindl, J. Laybourn-Parry, A.J. Hodson and B. Sattler. 2007. Viral dynamics in cryoconite holes on a high Arctic glacier (Svalbard). J. Geophys. Res., 112(G4), G04S31. (10.1029/2006JG000350.)

Anesio, A.M., A.J. Hodson, A. Fritz, R. Psenner and B. Sattler. 2009. High microbial activity on glaciers: importance to the global carbon cycle. Global Change Biol., 15(4), 955-960.

Anesio, A.M. and 6 others. 2010. Carbon fluxes through bacterial community on glacier surfaces. Ann. Glaciol., 51(56), 32-40.

Arendt, A. 1999. Approaches to modelling the surface albedo of a high Arctic glacier. Geogr. Ann., 81A(4), 477-487.

Bøggild, C.E. 1997. Different melt regimes indicated by surface albedo measurements at the Greenland ice sheet margin application of TM image. EARSeL Adv. Remote Sens., 5, Yearbook 1997, 82-88.

Bøggild, C.E., R.E. Brandt, K.J. Brown and S.G. Warren. 2010. The ablation zone in northeast Greenland: ice types, albedos and impurities. J. Glaciol., 56(195), 101-113.

Brock, B.W. and N.S. Arnold. 2000. A spreadsheet-based (Microsoft Excel) point surface energy balance model for glacier and snowmelt studies. Earth Surf. Process. Landf., 25(6), 649-658.

Christner, B.C., B.H. Kvito and J.N. Reeve. 2003. Molecular identification of bacteria and eukarya inhabiting an Antarctic cryoconite hole. Extremophiles, 7(3), 177-183.

Cook, J., A. Hodson, J. Telling, A. Anesio, T. Irvine-Fynn and C. Bellas. 2010. The mass-area relationship within cryoconite holes and its implications for primary production. Ann. Glaciol., 51(56), 106-110.

De Smet, W.H. and E.A. van Rompu. 1994. Rotifera and Tardigrada from some cryoconite holes on a Spitsbergen (Svalbard) glacier. Belg. J. Zool., 124(1), 27-37.

Edwards, A. and 7 others. 2011. Possible interactions between bacterial diversity, microbial activity and supraglacial hydrology of cryoconite holes in Svalbard. ISME J., 5(1), 150-160.

Etzelmüller, B., R.S. Ödegård, G. Vatne, R.S. Mysterud, T. Tonning and J.L. Sollid. 2000. Glacier characteristics and sediment transfer system of Longyearbreen and Larsbreen, western Spitsbergen. Nor. Geogr. Tidsskr., 54(4), 157-168.

Foreman, C.M., B. Sattler, D.L. Mikucki, D.L. Porazinska and J.C. Priscu. 2007. Metabolic activity and diversity of cryoconites in the Taylor Valley, Antarctica. J. Geophys. Res., 112(G4), G04S32. (10.1029/2006JG000358.)

Fountain, A.G., M. Tranter, T.H. Nylen, K.J. Lewis and D.R. Mueller. 2004. Evolution of cryoconite holes and their contribution to meltwater runoff from glaciers in the McMurdo Dry Valleys, Antarctica. J. Glaciol., 50(168), 35-45.

Hanssen-Bauer, I., M.K. Solås and E.L. Steffensen. 1990. The climate of Spitsbergen. Oslo, Norwegian Meteorological Institute. (DNMI Research Report 39/90.)

Hodson, A.J., A.M. Gurnell, R. Washington, M. Tranter, M.J. Clark and J.O. Hagen. 1998. Meteorological and runoff time-series characteristics in a small, high-Arctic glaciated basin, Svalbard. Hydrol. Process., 12(3), 509-526.

Hodson, A.J., M. Tranter and G. Vatne. 2000. Contemporary rates of chemical denudation and atmospheric $\mathrm{CO}_{2}$ sequestration in glacier basins: an Arctic perspective. Earth Surf. Process. Landf., 25(13), 1447-1471.

Hodson, A.J., P.N. Mumford, J. Kohler and P.M. Wynn. 2005a. The High Arctic glacial ecosystem: new insights from nutrient budgets. Biogeochemistry, 72(2), 233-256.

Hodson, A., J. Kohler and M. Brinkhaus. 2005b. Multi-year water and surface energy budget of a high-latitude polythermal glacier: evidence for overwinter storage in a dynamic subglacial reservoir. Ann. Glaciol., 42, 42-46.

Hodson, A.J. and 10 others. 2007. A glacier respires: quantifying the distribution and respiration $\mathrm{CO}_{2}$ flux of cryoconite across an entire Arctic supraglacial ecosystem. J. Geophys. Res., 112(G4), G04S36. (10.1029/2007JG000452.)

Hodson, A. and 7 others. 2008. Glacial ecosystems. Ecol. Monogr., 78(1), 41-67.

Hodson, A. and 6 others. 2010. The structure, biological activity and biogeochemistry of cryoconite aggregates upon an Arctic valley glacier: Longyearbreen, Svalbard. J. Glaciol., 56(196), 349-362.

Hood, E. and 6 others. 2009. Glaciers as a source of ancient and labile organic matter to the marine environment. Nature, 462(7276), 1044-1047.

Irvine-Fynn, T.D.L. 2008. Modelling runoff from the maritime Arctic cryosphere: water storage and routing at Midtre Lovénbreen. (PhD thesis, University of Sheffield.)

Irvine-Fynn, T.D.L., J.W. Bridge and A.J. Hodson. 2010. Rapid quantification of cryoconite: granule geometry and in situ supraglacial extents, using examples from Svalbard and Greenland. J. Glaciol., 56(196), 297-308.

Kreith, F. and J.F. Kreider. 1978. Principles of solar engineering. New York, McGraw-Hill.

Langford, H., A. Hodson, S. Banwart and C. Bøggild. 2010. The microstructure and biogeochemistry of Arctic cryoconite granules. Ann. Glaciol., 51(56), 87-94.

MacDonell, S. and S. Fitzsimons. 2008. The formation and hydrological significance of cryoconite holes. Progr. Phys. Geogr., 32(6), 595-610.

McIntyre, N.F. 1984. Cryoconite hole thermodynamics. Can. J. Earth Sci., 21(2), 152-156.

Mueller, D.R. and W.H. Pollard. 2004. Gradient analysis of cryoconite ecosystems from two polar glaciers. Polar Biol., 27(2), 66-74.

Müller, F. and C.M. Keeler. 1969. Errors in short-term ablation measurements on melting ice surfaces. J. Glaciol., 8(52), 91-105.

Podgorny, I.A. and T.C. Grenfell. 1996. Absorption of solar energy in a cryoconite hole. Geophys. Res. Lett., 23(18), 2465-2468.

Porazinska, D.L., A.G. Fountain, T.H. Nylen, M. Tranter, R.A. Virginia and D.H. Wall. 2004. The biodiversity and biogeochemistry of cryoconite holes from McMurdo Dry Valley glaciers, Antarctica. Arct. Antarct. Alp. Res., 36(1), 84-91.

Säwström, C., P. Mumford, W. Marshall, A. Hodson and J. Laybourn-Parry. 2002. The microbial communities and primary productivity of cryconite holes in an Arctic glacier (Svalbard $79^{\circ} \mathrm{N}$ ). Polar Biol., 25(8), 591-596.

Segawa, T., N. Takeuchi, K. Ishida, H. Kanda and S. Kohshima. 2010. Altitudinal changes in a bacterial community on Gulkana Glacier in Alaska. Microbes Environ., 25(3), 171-182.

Stibal, M., M. Šabacká and K. Kaštovská. 2006. Microbial communities on glacier surfaces in Svalbard: impact of physical and chemical properties on abundance and structure of cyanobacteria and algae. Microbial Ecol., 52(4), 655-654.

Stibal, M., M. Tranter, L.G. Benning and J. Rehák. 2008. Microbial primary production on an Arctic glacier is insignificant in comparison with allochthonous organic carbon input. Environ. Microbiol., 10(8), 2172-2178.

Takeuchi, N. 2009. Temporal and spatial variations in spectral reflectance and characteristics of surface dust on Gulkana Glacier, Alaska Range. J. Glaciol., 55(192), 701-709.

Takeuchi, N., S. Kohshima, K. Goto-Azuma and R.M. Koerner. 2001a. Biological characteristics of dark colored material (cryoconite) on Canadian Arctic glaciers (Devon and Penny ice caps). Mem. Natl Inst. Polar Res., Special Issue 54, 495-505.

Takeuchi, N., S. Kohshima and K. Seko. 2001b. Structure, formation, and darkening process of albedo-reducing material (cryoconite) on a Himalayan glacier: a granular algal mat growing on the glacier. Arct. Antarct. Alp. Res., 33(2), 115-122.

Takeuchi, N., H. Nishiyama and Z. Li. 2010. Structure and formation process of cryoconite granules on Ürümqi glacier No. 1, Tien Shan, China. Ann. Glaciol., 51(56), 9-14. 